\title{
O protagonismo controverso dos mestrados profissionais em ensino de ciências
}

\author{
The controversial role of the professional master \\ in science teaching
}

Flavia Rezende ${ }^{1}$. Fernanda Ostermann ${ }^{2}$

Resumo: O aumento da implantação de cursos de mestrado profissional em ensino vem sendo indicador dos novos contornos das políticas de formação impostos pela CAPES como agência reguladora da formação de professores. Dada a atual predominância desses cursos na área de ensino, empreendemos uma reflexão sobre o papel dos mestrados profissionais na busca da qualidade da educação brasileira e, em particular, da educação em ciências. Para tal, o caminho metodológico apoiou-se em um quadro crítico da situação do Ensino Médio no país e em um referencial marxista sobre a formação docente. Tanto pelos aspectos curriculares, que variam muito de acordo com a recontextualização da legislação em cada realidade particular, quanto pelos aspectos estruturais que tentamos avaliar, foi possível chegar à conclusão de que o protagonismo dos mestrados profissionais em ensino em relação à qualidade da educação de nível Médio é, no mínimo, controverso, e que, portanto, não se pode tomá-lo como garantido. Palavras-chave: Mestrado profissional. Educação em ciências. Formação de professores. Políticas públicas.

\begin{abstract}
The growth in the foundation of professional master courses in the area of education indicates the new rules of formation politics imposed by CAPES as a regulation agency of teacher training. Given the current predominance of this kind of course in the area of education, we undertook a reflection on the role of professional master courses in the search for quality in Brazilian education and in particular, of science education. The methodological approach is based on a critical view of high school education in the country and on a Marxist framework about teacher training. Considering curricular aspects, which vary a lot according to legislation, recontextualization in each particular reality and structural aspects that we have evaluated, it was possible to conclude that the role of professional master courses related to the quality of education is at least controversial and therefore, it cannot be taken for granted.
\end{abstract}

Keywords: Professional master. Science education. School' teacher training. Public policy.

\footnotetext{
${ }^{1}$ Programa de Pós-Graduação em Ensino de Física, Instituto de Física, Universidade Federal do Rio Grande do Sul (UFRGS), Campus do Vale, Caixa Postal 15051, CEP 91501-970, Porto Alegre, RS, Brasil. E-mail: <flaviarezende@uol.com.br>

${ }^{2}$ Departamento de Física, Instituto de Física, Universidade Federal do Rio Grande do Sul (UFRGS), Porto Alegre, RS, Brasil.
} 


\section{Introdução}

As políticas educacionais implementadas tanto em países centrais quanto periféricos estão relacionadas à agenda de organismos internacionais, visando à adequação da educação às exigências do mercado mundial e à nova etapa de internacionalização do capitalismo. Maués (2011) concluiu - de uma análise da agenda da Organização de Cooperação e Desenvolvimento Econômico (OCDE) para a educação e formação de professores - que a preocupação com o que acontece nas escolas e com o currículo ganha centralidade e, a partir daí, é que o professor e a formação desse profissional passam a ser elementos-chave. A educação, segundo essa agenda, seria um dos motores do crescimento econômico, sendo necessário aproximá-la do modelo empresarial para que corresponda à lógica do mercado.

A despeito da crise vivida atualmente pela profissão docente, a autora percebeu que as medidas propostas no documento não visam às ações que garantam uma formação inicial e continuada com qualidade nem ao desenvolvimento de planos de cargos e salários que concedam ao professor um reconhecimento social. Nos diferentes países, as regulações advindas desse documento dão destaque à prestação de contas do professor em relação ao êxito ou ao fracasso escolar e, por isso, propõem que a política docente seja baseada em salários diferenciados de acordo com um suposto mérito mensurado por avaliações externas.

Assim, os professores têm sido criticados, sobretudo, por formação deficiente e pouca responsabilidade pelo desempenho dos estudantes. A partir dessa crítica, vêm sofrendo grande pressão para que apresentem melhor desempenho, especialmente no que diz respeito aos resultados dos estudantes nos exames nacionais e internacionais (SCHEIBE, 2010). Neste sentido, os governos vêm estabelecendo medidas que visam ampliar o controle do exercício profissional por meio de exames de certificação associados a incentivos financeiros. Instala-se o princípio da performatividade, que atua como uma forma de controle indireto ou a distância, que substitui a intervenção e a prescrição pelo estabelecimento de objetivos, pela prestação de contas, pela comparação e pela avaliação de desempenho (DIAS, 2009 apud PEREIRA; VELLOSO, 2012).

Ao mesmo tempo, a formação inicial flexibiliza-se desde a exigência para ingresso ao seu próprio conteúdo, e a formação continuada passa a ser mais valorizada. A formação docente passa a ser vista como muito "teórica" e afastada das demandas das escolas e da sociedade. Essa apreciação, realizada por organismos internacionais, só faz sentido, obviamente, frente às novas exigências de preparação das pessoas para um mercado mais competitivo e globalizado. Segundo Freitas (2007), o novo receituário da formação incluía: “universitarização"/profissionalização (aligeirada), a ênfase na formação prática/validação das experiências, a formação continuada, a educação a distância e a pedagogia das competências. Essa "universitarização" aligeirada anula as experiências bem-sucedidas ocorridas, e se coloca como se nada existisse enquanto formação em nível Superior. Ao desprezar os saberes epistemológicos e teóricos, torna-se distante a possibilidade de formar um profissional crítico, analítico, e que possa dar conta dos processos sociais e políticos vivenciados pelos agentes sociais. Kuenzer (1999) já demonstrara que, dados o aligeiramento e a desqualificação da formação, tais políticas inviabilizam a construção da identidade do professor como cientista da educação, para constituí-lo como tarefeiro.

Freitas (2007) também identifica, entre gestores educacionais alinhados com a atual visão, o entendimento de que, se as transformações em todos os domínios do conhecimento 
têm-se dado de forma acelerada, caberia à formação inicial apenas dar noções mais gerais, deixando todo o resto a cargo da formação contínua. Esse diagnóstico abre um enorme mercado de formação, tanto nas universidades públicas quanto nas demais instituições de ensino e, mesmo, nas empresas.

Também Santos (2000), ao analisar a implementação de políticas do Banco Mundial (BM) para a formação docente, sinaliza a priorização da formação continuada em relação à formação inicial. Além da educação em serviço apresentar-se como uma forma mais barata e mais eficiente de formar profissionais para a educação, o investimento na educação continuada proposto pelo BM privilegia o conhecimento do conteúdo das matérias, alegando que ele tem mais influência no rendimento dos alunos do que o conhecimento pedagógico que os professores venham a ter. A perspectiva de melhorar o desempenho do professor visa, também, a instrumentalizá-lo para seguir diretrizes e normas curriculares definidas pelas políticas públicas.

A formação docente a serviço da nova etapa do capitalismo globalizado restringirse-ia ao estudo de métodos específicos para ensinar determinados conteúdos considerados prioritários, em detrimento de conhecimentos teóricos e do debate ideológico, considerado secundário (ARCE, 2001). Nestes moldes, a autora considera muito provável que estejamos "diante de uma retomada do tecnicismo sob novas bases: uma espécie de neotecnicismo" (FREITAS, 1995 apud ARCE, 2001, p. 127).

Essa caracterização da formação docente pode ser observada, segundo Arce (2001), na nova configuração que vem se dando à pós-graduação a partir de 2000 , com a criação dos cursos de pós-graduação em ensino de ciências e matemática ${ }^{3}$ separados da área de Educação na Coordenação de Aperfeiçoamento de Pessoal de Nível Superior (Capes), e com a abertura de mestrados profissionais (MP) na área da formação de professores, separados dos mestrados acadêmicos (MA) da área da Educação. O aumento da criação dos MP é indicador, para a autora, dos novos contornos das políticas de formação impostos pela Capes como nova agência reguladora da formação de professores. Entre os objetivos dessa agência, estaria, segundo ela, o de implantar um sistema de avaliação para formação docente nos moldes do que a instituição adota para a pós-graduação.

O crescimento dos MP tem conferido a esse tipo de curso posição de aparente "vocação" da antiga área de Ensino de Ciências e Matemática. Esta vocação teve início em 2002, quando foi criado, na Universidade Federal do Rio Grande do Sul (UFRGS), o primeiro curso de MP dessa área, especificamente de Ensino de Física, que serviu de modelo para outros cursos que o sucederam, em vários estados do Brasil. A indução da criação desse tipo de mestrado pela Capes resultou em um maior número de cursos de MP que de $\mathrm{MA}^{4}$ na atual área de Ensino. Neste cenário, observa-se um protagonismo já consolidado dos cursos de MP em Ensino de ciências, subárea na qual foram pioneiros e tiveram grande alcance.

\footnotetext{
${ }^{3}$ A área de Ensino de Ciências e Matemática deixou de existir em 2011 e passou a fazer parte da grande área de Ensino.

${ }^{4}$ Os cursos de MP compõem, atualmente, 58\% da área de Ensino, conforme dados divulgados pela CAPES no Relatório da Avaliação Trienal de 2013.
} 
Neste contexto, também ocorreram mudanças na área acadêmica no que diz respeito ao papel dos cursos de mestrado profissional em ensino. Antes vista com desconfiança e resistência pela área de Educação, a formação de professores em serviço no âmbito dos mestrados profissionais em ensino, nos dias de hoje, é reconhecida como um caminho importante para melhorar a educação brasileira pela Capes e pela comunidade acadêmica, compreendendo tanto a área de Educação como a área de Ensino. No documento "Comunicado Conjunto No 001/2013 - Áreas de Ensino e de Educação - Perspectivas de Cooperação e Articulação” (COORDENAÇÃO DE APERFEIÇOAMENTO DE PESSOAL DE NÍVEL SUPERIOR, 2013), de 28 de junho de 2013, percebe-se a ênfase na formação de professores e a esperança depositada nos mestrados profissionais para responder às demandas da educação "para o desenvolvimento brasileiro", e para enfrentar obstáculos e desafios como "a universalização e qualificação da Educação Básica". No entanto, essas afirmativas podem ser consideradas, no mínimo, apressadas, na medida em que ainda continua válida a observação de Ostermann e Rezende (2009, p. 69) de que seria necessária "uma reflexão aprofundada sobre a natureza dos cursos de mestrado profissional em ensino e sobre seu possível impacto na sociedade brasileira", questão ainda praticamente ausente da produção acadêmica das áreas de Educação e de Ensino.

Tomar os MP em ensino como objeto de estudo, para investigar suas possibilidades de contribuir para a qualidade da educação, nos parece crucial no atual cenário em que estes cursos representam um importante investimento da Capes na formação continuada de professores no âmbito da pós-graduação. O caminho metodológico apoia-se em um quadro crítico da situação do Ensino Médio e em um quadro conceitual sobre a formação docente. Com base nestes quadros e tomando-se como referência a proposta inicial do curso de MP em Ensino de Física da UFRGS, propõe-se uma reflexão sobre o papel dos MP em ensino na educação brasileira e, em particular, na educação em ciências.

\section{O ensino de ciências de nível Médio}

A situação atual do Ensino Médio brasileiro relaciona-se com a problemática dos MP na medida em que, com essa política, o governo pretende melhorar a formação dos professores de nível Médio, visando à qualidade da Educação Básica. A intenção não é colocar em discussão os dados referentes ao Ensino Médio, o que exigiria uma revisão muito mais ampla da literatura. Para a finalidade que pretendemos, optamos por traçar um quadro com base em dados oficiais, e trazer comentários críticos sobre estes dados de modo que nos sirvam para discutir o papel dos MP na seção final. Ainda que a responsabilidade por intervir neste quadro seja prioritariamente das licenciaturas, e não dos cursos de MP, consideramos que, de acordo com a Capes, esses cursos são uma parte importante da política atual de formação docente.

Com base em dados do Instituto Nacional de Estudos e Pesquisas Educacionais Anísio Teixeira (INEP), Kuenzer (2010) caracteriza a situação atual do Ensino Médio, começando pela análise do número de matrículas, que mostra: um crescimento de 32,1\% entre 1996 e 2001; de apenas 5,6\% no quinquênio seguinte; passando a decrescer a partir de 2007, configurando crescimento negativo de $-8,4 \%$ de 2000 a 2008. A distorção idade-série cresceu de 0,38 para 0,54 entre 2000 e 2007. 
Em 2007, 41,3\% das matrículas foram feitas no turno noturno por alunos de 18 anos ou mais, o que indica que, em sua maioria, trata-se de alunos que trabalham ou procuram trabalho. A administração pública estadual foi responsável por, aproximadamente, $85,8 \%$ das matrículas em 2008, que, somadas às federais, representam, aproximadamente, $87 \%$, sendo estes percentuais estáveis nos últimos anos.

Em termos de desempenho, os dados mostram o crescimento: da taxa de repetência de $18,65 \%$ em 2000, para 22,6\% em 2005; de evasão, de 8,0\% em 2000, para 10,0\% em 2005; do tempo médio de conclusão de $3,7 \%$ para 3,8\% no mesmo período.

A partir desse quadro, Kuenzer (2010) conclui que não houve avanço do Ensino Médio em relação à expansão do acesso, permanência e sucesso, no período 2000-2010, considerando, então, esta década como perdida. As conclusões são semelhantes em relação à infraestrutura. A autora aponta o baixo investimento por aluno feito pelo Ministério da Educação (MEC) (menor que o da Argentina e o do Chile, e muito menor do que a Organização para a Cooperação e Desenvolvimento Econômico sugere), como justificativa, em grande parte, por tal fracasso.

Para avaliar a qualidade do ensino oferecida, a autora traz os dados do Exame Nacional do Ensino Médio (ENEM) de 2009, que mostram que os mil piores resultados foram obtidos por escolas públicas, sendo $97,8 \%$ estaduais. Uma análise dos dados mais recentes do exame, disponíveis no MEC, referentes ao ENEM de 2011, mostrou que esse exame reflete as desigualdades sociais, e que a rede pública estadual apresenta as menores médias. A análise realizada chega à mesma conclusão de Travitzki (2013), de que “[...] a educação de um país não pode ser muito melhor que o país. [...] Precisamos melhorar as escolas, mas precisamos também reduzir nossas desigualdades".

Kuenzer (2010) oferece-nos uma imagem significativa da situação atual do Ensino Médio no Brasil quando sintetiza:

Para os filhos da burguesia e pequena burguesia, as escolas médias de educação geral ofertadas pela iniciativa privada atendem às suas demandas de acesso ao ensino superior; para os estratos médios e para parcela menos precarizada da classe trabalhadora, os cursos de educação profissional e tecnológica ofertados pelo setor público, embora de reduzida oferta, atendem à necessidade de inserção no mercado de trabalho, com o que viabilizam seu acesso ao ensino superior, na busca por ascensão social. (KUENZER, 2010, p. 867)

A autora supracitada avança na análise do Ensino Médio no país, considerando a questão da qualidade social, tomando como referência a dualidade estrutural da sociedade capitalista. Admitindo que a divisão entre trabalho intelectual e trabalho prático - e, por conseguinte, entre educação geral e profissional - tem sua origem na separação entre a propriedade dos meios de produção e a propriedade do trabalho, afirma que sua superação não é uma questão a ser resolvida por meio da educação, mas pela superação da contradição entre a propriedade dos meios de produção e a propriedade da força de trabalho.

A hipótese de que nos anos de 1990 este modelo começou a ser invertido na esteira das políticas do BM, que propunham, para os países pobres, a educação geral para os jovens, é examinada por Kuenzer (2010). Infelizmente, diante do quadro que traça do Ensino Médio, a 
autora conclui que "quando a modalidade de educação geral passou a ser disponibilizada para os trabalhadores sob o discurso de sua democratização, isso foi feito de forma desqualificada" (KUENZER, 2010, p. 865).

\section{Um olhar crítico sobre a formação docente}

Esperamos, com esta seção, traçar um quadro conceitual sobre a formação docente que nos permita avançar na discussão sobre a formação oferecida pelos MP em ensino de ciências.

Kuenzer (2011) vê, na formação de professores, o desafio de superar a falsa consciência da suposta neutralidade das políticas e propostas de formação, considerando, assim, o espaço de formulação e implementação de políticas enquanto um campo de disputas. Apoiando-se no referencial marxista, ela pressupõe que, independentemente do nível, da etapa ou da modalidade de educação, no capitalismo não há um projeto único, ou neutro, de formação de professores. Entretanto, a autora julga que, apesar disso, “o campo da formação de professores tem sido tratado por sobre as diferenças de classe, como se o simples fato de exercer a profissão docente isentasse esses profissionais de valores, concepções e compromissos de classe" (KUENZER, 2011, p. 669). Em sua visão, o processo pedagógico não é universal, sendo necessário elucidar a quem ele serve e explicitar suas contradições, visando ao desenvolvimento de relações realmente democráticas. Assim, se há projetos pedagógicos contraditórios, "não existe uma única proposta de formação de professores, mas propostas que se diferenciam a partir das formas históricas de organização e gestão de trabalho, visando atender à divisão social e técnica que o trabalho assume em cada regime de acumulação" (KUENZER, 2011, p. 670).

A autora traça um quadro da formação de professores no Brasil com base no Censo Escolar da Educação Básica de 2009 (INSTITUTO NACIONAL DE ESTUDOS E PESQUISAS EDUCACIONAIS ANÍSIO TEIXEIRA, 2011), no qual mostra que 87\% dos 461.542 professores que atuam no Ensino Médio são formados em cursos de licenciatura, $75 \%$ atuam exclusivamente na rede estadual, dos quais $95 \%$ em área urbana. Ela mostra, porém, que é grande a desigualdade da distribuição da qualificação entre as disciplinas: apenas $53 \%$ dos professores que atuam no Ensino Médio têm formação compatível com a disciplina que lecionam, sendo a maior distorção em Física, em que apenas 25,7\% têm formação específica ${ }^{5}$.

Apesar de deixar evidente a necessidade de esforço intensivo na formação inicial de professores, a autora lembra que este esforço poderá não ser o bastante, tendo em vista que apenas entre 30 e 40\% dos licenciados formados nos últimos 25 anos atuam na Educação Básica. Estes dados reiteram a recomendação, que já vem sendo apontada por outros autores, de que a política de formação deve ser integrada à estruturação da carreira docente, à política salarial que assegure dignidade ao professor e garantia de condições adequadas de trabalho.

Em outra direção, a ação da Capes como agência reguladora da formação de professores desenvolve-se mediante vários programas que apoiam a integração entre as instituições de Ensino

\footnotetext{
${ }^{5}$ Estudos mais atuais, mas de menor porte, indicam que o quadro descrito por Kuenzer (2011) mantém-se, praticamente, inalterado.
} 
Superior públicas ou comunitárias e as escolas de Educação Básica, financiando o desenvolvimento de: inovações, materiais didáticos, práticas dos licenciandos e cursos de pós-graduação lato e stricto sensu, mediante custeio e bolsas.

Dado o volume de investimento nesses programas, Kuenzer (2011) considera que eles precisarão ser avaliados em relação ao impacto na qualidade do trabalho escolar, uma vez que estudos específicos sobre a formação continuada de professores e de trabalhadores em geral mostram que "a qualificação individual tem impacto reduzido sobre a qualidade do trabalho, quando não se insere em uma dinâmica mais ampla e intencional de qualificação do coletivo de professores a partir da escola" (KUENZER, 2011, p. 674). Segundo a autora, é preciso desenvolver "processos intencionais e sistematizados que envolvam os docentes que atuam na mesma escola ou, pelo menos, no mesmo processo pedagógico, uma vez que, pela via do trabalho individual, não existe possibilidade de transformação" (KUENZER, 2011, p. 674). A autora já afirmara antes, que a formação em nível de mestrado e doutorado não contempla, para o professor, efetiva formação para o ensino em qualquer nível, quando se concentra em conhecimentos específicos das áreas de estudo (KUENZER, 2010).

Para Kuenzer (2011, p. 676), “o debate sobre formação de professores permanece nos limites da lógica da reprodução capitalista, sem a necessária compreensão do seu caráter ideológico". Como consequência desta compreensão parcial, ela aponta a crença de que, com um bom percurso formativo, teremos bons professores. A autora indica, no entanto, outra lógica possível, que implica "a análise das propostas de formação a partir da realidade do trabalho docente inserido no modo de produção capitalista, a partir do entendimento das dimensões pedagógicas das relações sociais e produtivas” (KUENZER, 2011, p. 676). A partir dessa análise, a autora considera que:

[...] as propostas curriculares de formação de professores podem estimular as práticas revolucionárias ou retardá-las, à medida que permitam ou não a compreensão do mundo do trabalho capitalista com todas as suas contradições; que possibilitem o desenvolvimento de práticas conservadoras ou estimulem o desenvolvimento de sujeitos críticos e criativos, comprometidos com a construção de outras relações sociais. (KUENZER, 2011, p. 678)

Sendo assim, a autora supracitada conclui que as concepções ontológicas e epistemológicas, e consequentes concepções de homem, de trabalho e de sociedade, que sustentam propostas curriculares, são fundamentais para julgar a qualidade da formação e profissionalização de professores.

Para pensar o conteúdo da formação docente, aprendemos, com Kuenzer (1999, p. 166), que

[...] não existe um modelo de formação de professores a priori, mas modelos que se diferenciam, dadas as concepções de educação e de sociedade que correspondem às demandas de formação dos intelectuais em cada etapa de desenvolvimento das forças produtivas, em que se confrontam finalidades e interesses que são contraditórios. 
Está claro que as mudanças impostas ao mundo do trabalho e das relações sociais a partir do final de século passado deram origem a novas demandas de educação, configurando um novo processo pedagógico. Já naquela época, a autora considerava que os professores precisavam compreender estas relações a fim de que a educação pudesse contribuir para a construção de uma sociedade democrática.

Mais recentemente, ainda defendendo a necessidade de entendimento das dimensões pedagógicas das relações sociais e produtivas, Kuenzer (2011, p. 684) propõe que a primeira dimensão a ser considerada na formação do professor comprometido com seu trabalho é:

[...] a capacidade de, apoiando-se nas ciências humanas, sociais e econômicas, compreender as mudanças ocorridas no mundo do trabalho, construindo categorias de análise que lhe permitam apreender as dimensões pedagógicas presentes nas relações sociais e produtivas, de modo a identificar as novas demandas de educação e a que interesses elas se vinculam. Ou seja, compreender historicamente os processos de formação humana em suas articulações com a vida social e produtiva, as teorias e os processos pedagógicos, de modo a ser capaz de produzir conhecimento em educação e intervir de maneira competente nos processos pedagógicos amplos e específicos, institucionais e não institucionais, com base em uma determinada concepção de sociedade.

Os contornos da formação elencados até agora estão em sintonia com a proposta do grupo de professores e formadores que defendem a agenda pela justiça social nos Estados Unidos, que, segundo Zeichner (2008 apud DINIZ-PEREIRA, 2008), enfatizam, na formação docente, valores coletivistas, de solidariedade e de transformação da sociedade a partir da sala de aula. Este grupo preocupa-se em ajudar futuros docentes a enxergarem as implicações políticas e sociais de suas ações e o contexto no qual eles trabalham, bem como a perceberem que suas escolhas e/ou decisões cotidianas estão ligadas a eixos de continuidade (reprodução do status quo) ou de mudança, transformação e resistência.

Zeichner (2008) revê posturas anteriores e dá uma guinada ao afirmar que a formação do professor reflexivo não valerá a pena se não envolvermos a formação docente na luta contra a atual situação política e econômica na maior parte do mundo. Essa nova proposta trabalharia contra esta situação e ligaria o que fazemos nas salas de aula com as lutas dos educadores e demais cidadãos em todos os lugares, visando uma vida mais igualitária em termos de meios e condições de vida.

Com relação ao lócus da formação docente, segundo Lage, Urzetta e Cunha (2011), vários estudos sobre as tendências atuais da formação continuada apontam para a necessidade de se eleger a escola como o lócus privilegiado dessa formação. Também tem sido apontada a importância de se articular a formação desenvolvida no próprio local de trabalho a outras modalidades, tais como: cursos, congressos e atividades culturais. Lage, Urzetta e Cunha (2011) sinalizam que esta proposta depende, sobretudo, de medidas políticas que potencializem a formação continuada, passando a incluir, na jornada de trabalho, tempo para: a docência (aulas), atividades pedagógicas (reuniões, planejamento) e para atividades de formação contínua, coletivas e em serviço na própria escola e, também, fora dela. Estas condições tornariam possível a 
O protagonismo controverso dos mestrados profissionais ...

elaboração de um projeto coletivo de formação continuada no qual toda a comunidade escolar possa reunir-se para repensar o trabalho em desenvolvimento e procurar estimular componentes formativos que tenham uma articulação com o cotidiano escolar e com a prática pedagógica.

\title{
Uma proposta de curso de mestrado profissional em ensino de física
}

No sentido de descrever as características básicas dos cursos de MP em ensino de Ciências, nos valemos da proposta inicial do curso de MP em Ensino de Física da UFRGS, que foi criado em 2002 e serviu de modelo para outros cursos que o sucederam em vários estados do Brasil. Ainda que o lócus da formação seja a universidade, é exigido que o candidato esteja em exercício de docência em Física. A integralização curricular deve ocorrer, no máximo, em três anos, sendo as aulas oferecidas em apenas um dia da semana e de forma intensiva nos períodos de recesso escolar. O corpo docente era constituído, na sua criação, em sua maioria, por docentes com Doutorado em Física ou área afim. Na proposta inicial do curso, os elaboradores apontam como objetivo do curso:

\begin{abstract}
Melhoria da qualificação profissional de professores de Física do nível médio e das Licenciaturas em Física ou afins, em plena atividade no sistema de ensino, em termos de conteúdos de Física, de aspectos teóricos, metodológicos e epistemológicos do ensino da Física, e do uso de novas tecnologias. (UNIVERSIDADE FEDERAL DO RIO GRANDE DO SUL, 2001)
\end{abstract}

Tal objetivo parece fundamentar-se na concepção de que, oferecendo conteúdos e trabalhando a racionalidade dos professores a partir do domínio de novos conhecimentos, o curso de MP produziria a melhoria da Educação Básica. Do mesmo modo, percebe-se que os problemas da escola não constituíram a origem para a formulação do objetivo do curso. Os conhecimentos listados deixam de explicitar os aspectos pedagógicos e todos aqueles relacionados à área das ciências humanas. O uso de novas tecnologias no ensino é mencionado, mas, novamente, essa demanda não parte da realidade escolar, ou da realidade do professor, mas, sim, de especialistas acadêmicos que julgam serem esses os elementos necessários para aprimorar a qualificação do docente e que, consequentemente, terão impacto na qualidade do Ensino Médio.

As disciplinas obrigatórias e opcionais, que fazem parte do currículo, contemplam, segundo a proposta: a formação em Física, a formação didático-pedagógica relevante ao ensino da Física, a prática docente supervisionada e a elaboração de um trabalho final de pesquisa profissional. Pela escolha da ordem desses elementos, podemos supor a ordem de importância dada pelos elaboradores aos tipos de formação propostos. A formação conteudista, típica do modelo de racionalidade técnica, é a primeira e será proporcionada por disciplinas obrigatórias e opcionais.

Naquele momento de criação do curso e de outros que vieram logo a seguir, tornou-se hegemônico na antiga área de Ensino de Ciências que o desenvolvimento de um produto educacional - como, por exemplo, programas de computador, textos didáticos para alunos, textos de apoio aos professores, vídeos, equipamentos, páginas na internet, pôsteres e experimentos 
- seria obrigatório como trabalho de conclusão do MP, caracterizando-se como a diferença essencial entre este e o MA. Recentemente, este tipo de curso foi considerado como indutor da qualidade do ensino de ciências por algumas sociedades científicas, o que deu origem a cursos de MP em ensino de caráter nacional. A exemplo da Sociedade Brasileira de Matemática, que criou, em 2011, um curso de MP em Ensino de Matemática em rede nacional, a Sociedade Brasileira de Física (SBF) criou, em 2012, com base no modelo descrito, um MP em Ensino de Física de caráter nacional, cuja estrutura administrativa está centralizada numa comissão organizada pela própria SBF e que conta com polos distribuídos em instituições de Ensino Superior de vários estados.

\section{Discussão e considerações finais}

Indubitavelmente, uma reflexão sobre a formação continuada realizada pela via dos MP em ensino está inserida em um cenário de desvalorização da atividade docente, visto que, nos dias de hoje, a docência vem sendo considerada, pelos jovens, como opção profissional cada vez menos atrativa. Scheibe (2011) atribui este cenário à fragmentação das ações nas políticas públicas de formação dos profissionais do magistério da Educação Básica, o seu aligeiramento e investimento não suficiente de recursos. Para a autora, as medidas que visam à formação se não são totalmente dispensáveis, precisam "[...] ser relativizadas frente aos salários nada compensadores, carreiras que não oferecem clareza de percurso, imaginário coletivo desmotivado em relação à profissão, alto índice de abandono da docência e a progressiva queda na procura pelos cursos de licenciatura" (SCHEIBE, 2010, p. 985).

Beraldo, Gobatto e Costa (2011) constatam que este cenário é traçado na própria lei. Segundo os autores, o texto apresentado no Decreto 6.755/09 (BRASIL, 2009) não expressa entendimento de que um dos requisitos básicos para a educação de qualidade é a valorização dos profissionais da educação.

Todos estes fatores implicados na desvalorização da carreira docente são determinantes para a qualidade da educação e precisam de políticas educacionais e ações que possam reverter a sobrecarga de trabalho dos professores e a desvalorização profissional, sem as quais a carência de professores das ciências da natureza tenderá a aumentar. Talvez, por isso, Gatti (2008) acredita que investir mais orçamento público na formação de licenciados em instituições públicas e investir na qualificação desses cursos, em termos de projeto, de docentes, de infraestrutura, seria uma política mais condizente para a melhor qualificação dos trabalhadores nas redes de ensino do que a educação continuada, que deveria voltar-se realmente para os aperfeiçoamentos ou especializações.

Essa controvérsia reforça a necessidade de discutirmos a política de formação continuada que está em curso e em crescimento neste momento, representada pelos MP em ensino. A partir do nosso quadro teórico sobre a formação docente é possível observar uma série de problemas curriculares na formação inicial do professor, que podem ser igualmente alvo de discussão em relação aos cursos de MP. Kuenzer (2011) enfatiza a necessidade de estudos e práticas que permitam ao professor 
[...] apropriar-se das diferentes formas de leitura e interpretação da realidade que se constituem em objeto de vários campos do conhecimento, mas em particular da filosofia, da história, da sociologia e da economia, bem como estabelecer interlocução com os vários especialistas. (KUENZER, 2011, p. 684)

Além dessas competências, a autora também considera necessário que o professor saiba selecionar conteúdos, organizar situações de aprendizagem de modo a desenvolver, nos alunos, as capacidades de leitura e interpretação do texto e da realidade, promovendo situações que os permitam transitar do senso comum para o comportamento científico.

No mesmo sentido, Gatti (2010) deixa claro que a formação de professores (seja inicial ou continuada) não pode ser pensada como adendo das disciplinas científicas, mas a partir da função social própria à escolarização, que inclui tanto o conhecimento acumulado como os valores e práticas sociais. Arce (2001) também reafirma que a formação de professores exige uma bagagem filosófica, histórica, social e política, além de uma sólida formação didáticometodológica, visando formar um profissional capaz de teorizar sobre as relações entre educação e sociedade e que, a partir dessa análise teórica, possa propor mudanças significativas na educação. A violência, a drogadição, a crise de autoridade dos professores e os baixos salários, que levam à intensificação do trabalho docente e, até, a problemas de saúde, são exemplos de fenômenos atuais trazidos por Cunha (2013), para mostrar que a formação e o exercício docente exigem uma relação intrínseca com o contexto social, seus valores e tensões. Problematizações do contexto social não têm lugar em propostas curriculares como a que descrevemos, o que indica, claramente, a necessidade de criação de espaço para discussões sobre estes e outros aspectos atuais da educação brasileira, incluindo as políticas curriculares, as finalidades do Ensino Médio e o significado do ensino de ciências na sociedade, procurando desvendar a quem servem e explicitar as contradições.

Entre todos estes desafios para a formação docente, Kuenzer (2011, p. 686) acrescenta a competência para "suprir, em uma escola precarizada, com condições de trabalho cada vez piores, as deficiências culturais e cognitivas decorrentes da origem de classe da maioria dos alunos". Para isso, segundo a autora, o professor

[...] deverá estar capacitado para trabalhar com as diferenças, desde a sua correta identificação até a seleção de conteúdos, caminhos metodológicos e formas de avaliação, de modo a minimizá-las, no que diz respeito às relações com o conhecimento e ao desenvolvimento das competências cognitivas complexas. E sem poder contar com os recursos necessários e com a devida retribuição salarial, o que vai lhe exigir mais esforço, competência, criatividade e compromisso. (KUENZER, 2011, p. 686)

Diante do quadro alarmante em que se encontra o Ensino Médio público, somos levadas a pensar que precisamos de outros modelos de programas de formação inicial e continuada de professores, mais adequados 
[...] à nova realidade do jovem que vive em relações sociais e produtivas marcadas pela exclusão, pela ausência de projeto de futuro, pela complexidade tecnológica e dos meios de comunicação, pela flexibilidade, pela instabilidade, pela intensificação e pelo estresse. (KUENZER, 2010, p. 869)

O investimento nos MP em ensino vai na contramão dessa recomendação ao não levar em conta a realidade social do aluno e a situação atual do Ensino Médio público. Não é difícil imaginar os imensos obstáculos que teremos de transpor para formar professores que possam compreender a realidade social e política de seus alunos, conforme Kuenzer (2011) nos alerta, seja na formação inicial, continuada, e, sobretudo, nos MP em ensino.

Ainda são raras as pesquisas que trazem resultados sobre contextos de prática de cursos de MP. Uma pesquisa realizada recentemente com alunos do MP em Ensino de Física da UFRGS mostrou que, além do grande distanciamento entre as disciplinas oferecidas pelo curso e a realidade escolar, essa modalidade de formação não consegue superar o modelo de racionalidade técnica, já que reforça a aceitação dos regulamentos burocráticos e promove pouca apropriação do sentido de profissionalidade pelos professores (SCHÄFER; OSTERMANN, 2013a, 2013b). Um dos elementos levantados para explicar essas dificuldades foi a própria composição do corpo docente do curso, no qual predomina o "núcleo duro" da Física, que se utiliza do modelo de racionalidade técnica e encontra-se distante da realidade do Ensino Médio.

Embora seja evidente que os aspectos curriculares sejam extremamente importantes para avaliar a contribuição efetiva dos MP em ensino, não podemos avaliá-los homogeneamente, porque são claramente dependentes de processos de recontextualização da legislação pelo programa de pós-graduação no qual o MP está inserido. Obviamente que todas as políticas educacionais são recontextualizadas de formas particulares em diferentes estados, escolas, cursos de licenciaturas e MPs, e que estes processos de recontextualização são palcos de lutas que não são objeto do presente artigo, mas que precisariam ser futuramente investigados em estudos empíricos. Diante da variedade de MPs no ensino de ciências, resultantes dos processos de recontextualização, não há como generalizar e enquadrar todos eles nas afirmativas precedentes.

Não desconsiderando a importância dos aspectos curriculares, mas dada a heterogeneidade gerada pelos processos de recontextualização, julgamos mais relevante trazer para discussão aspectos estruturais, comuns a todos os cursos de MP em ensino. Um desses aspectos é o lócus da formação. A literatura tem enfatizado a necessidade de se trabalhar com o conjunto dos professores das escolas. Kuenzer (2011) deixa claro que as ações de formação continuada individuais não trazem resultado efetivo para contexto escolar. Além da necessidade de serem coletivos, os processos de formação continuada precisam ser centrados nos problemas cotidianos dos docentes, e não se configurarem enquanto formação escolar, explorando aspectos teóricos, pouco sintonizados com a realidade cotidiana das escolas. Estas recomendações vão na contramão da configuração dos cursos de MP em ensino. $\mathrm{O}$ aspecto da formação individual está presente em todos os cursos de MP, a exemplo dos mestrados acadêmicos, centrados em defesas individuais e na formação individual do aluno. $O$ investimento na formação docente individual por meio dos cursos de MP tem, assim, pouco impacto sobre a qualidade da educação por deixar de captar uma dinâmica mais ampla e intencional do coletivo de professores a partir da escola. 
A importância da interlocução entre docentes no ambiente escolar e sua correlação com a qualidade da educação foram observadas em um estudo recente (SCHWARTZ; REZENDE, 2013), que evidenciou o maior potencial da discussão coletiva do que o de políticas oficiais para moldar perspectivas docentes, ganhando alcance superior na busca da qualidade, justamente porque o docente se reconhece na proposta e a defende legitimamente. Estes resultados apontam, assim, no mesmo sentido das análises de Kuenzer (2011), indicando que o processo de formação docente não deveria ser realizado individualmente e longe da escola, mas integrado à atuação docente, considerando a dimensão formativa da discussão entre docentes, coordenação e direção na instituição.

Outro aspecto que parece vigorar em quase todos os cursos de MP em ensino de ciências é a obrigatoriedade do desenvolvimento de um produto educacional como parte do trabalho de conclusão. Ostermann e Rezende (2009) sinalizaram o ranço tecnicista da concepção de produto educacional, pois, ao se elaborar um produto final, está-se dando prioridade ao como ensinar, e não ao por quê ou ao quê, além de estar implícito que a introdução de um produto trará qualidade ou solucionará os problemas educacionais. Para as autoras, seria necessário investir em produtos que não apenas contemplam a eficiência de um método de ensinar dado conteúdo, mas que envolvessem a reflexão sobre o problema educacional vivido pelo professor em uma dada realidade escolar e sobre as finalidades da educação em ciências na contemporaneidade.

O documento conjunto das áreas de Ensino e Educação da Capes, por outro lado, considera indiscutível a contribuição dos cursos de MP para o enfrentamento dos desafios da educação no Brasil, defendendo iniciativas de articulação entre essas áreas, para o desenvolvimento de ações conjuntas e a necessidade de dar visibilidade à produção acadêmica e técnica desses cursos, que se expressa pelos produtos educacionais desenvolvidos pelos professores -alunos. Cabe aqui analisar criticamente a visão de que esses produtos podem proporcionar impacto relevante sobre a qualidade da educação brasileira, já que são muitos os limites impostos à suposta efetividade dos produtos elaborados. Além de o desenvolvimento do produto ter apenas o papel de cumprir uma etapa obrigatória para a conclusão do curso, em geral, a validade educacional de tal produto é comprometida por contingências tanto do curso como da escola, relacionadas, por exemplo: à sua concepção, implementação pró-forma, falta de autonomia do professor no contexto escolar, descontinuidade, pouca disseminação na escola e pouca qualidade (SCHÄFER, 2013).

Outro aspecto preocupante da formação docente em nível de MP é o destino dos egressos. No estudo do curso de MP em ensino de Física da UFRGS, Schäfer e Ostermann (2013a) concluíram que a maioria dos professores egressos não permaneceu na escola em que lecionava ao ingressar no curso, tendo migrado para o Ensino Superior (privado, em geral) ou para os Institutos Federais de Educação, Ciência e Tecnologia (IFET). Este fenômeno, que pode ser comum a muitos cursos semelhantes do país, acaba por provocar o deslocamento de professores da rede pública estadual, onde se encontra a maior demanda por matrículas no Ensino Médio, para instituições que respondem por apenas 1,2\% do total de matrículas nesse nível de ensino, e que é colocada como alvo da política da Capes. Além desta distorção, os professores egressos dos MPs que passam a atuar nos IFETs não receberam uma formação especial para lidar com o Ensino Médio integrado recomendada por Kuenzer (2011).

Na prática, em vez de proporcionarem a melhoria da Educação Básica intencionada pela Capes, os MP estão alimentando a mesma reprodução que ocorre na educação de nível 
Médio, no âmbito da atuação docente. A breve análise da reprodução das diferenças sociais no Ensino Médio, abordada anteriormente, foi importante para enxergarmos, analogamente, a reprodução dessa configuração na formação docente. A licenciatura é relegada a alunos que não conseguem cursar outros cursos de maior prestígio e adquirem uma profissão que tem menos prestígio ainda; ao passo que os MP servem para alavancar um pequeno grupo destes professores para atuarem nos IFET ou em instituições de Ensino Superior que representam, igualmente, o ingresso em outro nível social. Um interesse para estudo futuro seria investigar se esta reprodução de diferenças sociais já se colocaria na clientela que procura os MPs, que já teria condições sociais e educacionais para cursar uma pós-graduação.

Tanto pelos aspectos curriculares, que variam muito de acordo com a recontextualização da legislação para cada realidade particular do país, quanto pelos aspectos estruturais que tentamos avaliar, é possível chegar à conclusão de que o protagonismo dos MP em ensino em relação à qualidade da educação de nível Médio é, no mínimo, controverso, isto é, não é algo que se possa tomar como garantido. Esta conclusão e a discussão empreendida neste trabalho não se propõem a substituir nenhuma pesquisa que tenha como objeto contextos de prática de cursos de MP em ensino, mas a oferecer uma reflexão teórica que poderá servir de suporte para futuros estudos empíricos.

\section{Referências}

ARCE, A. Compre o kit neoliberal para a educação infantil e ganhe grátis os dez passos para se tornar um professor reflexivo. Educação \& Sociedade, Campinas, v. 22, n. 74, p. 251-283, 2001. Disponível em: <http://dx.doi.org/10.1590/S0101-73302001000100014>. Acesso em: 12 maio 2015.

BERALDO, T. M. L.; GOBATTO, M. R.; COSTA, F. T. Política nacional para a formação de professores em exercício: uma análise da área das ciências da natureza. In: ENCONTRO NACIONAL DE PESQUISA EM EDUCAÇÃO EM CIÊNCIAS, 8., 2011, Campinas. Anais... Campinas: ABRAPEC, 2011. Disponível em: <http://www.nutes.ufrj.br/abrapec/ viiienpec/resumos/R1484-1.pdf>. Acesso em: 12 maio 2015.

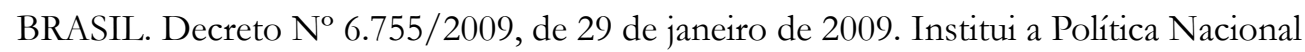
de Formação dos Profissionais do Magistério da Educação Básica, disciplina a atuação da Coordenação de Aperfeiçoamento de Pessoal de Nível Superior - CAPES no fomento a programas de formação inicial continuada, e dá outras providências. Diário Oficial da União, Brasília, 30 jan. 2009. Disponível em: < http://www.planalto.gov.br/ccivil_03/_ ato2007-2010/2009/decreto/d6755.htm>. Acesso em: 12 maio 2015.

COORDENAÇÃO DE APERFEIÇOAMENTO DE PESSOAL DE NÍVEL SUPERIOR. Comunicado conjunto $\mathrm{N}^{\mathbf{0}} \mathbf{0 0 1 / 2 0 1 3}$ : áreas de ensino e de educação - perspectivas de cooperação e articulação. Brasília, 2013. Disponível em: <http:/ /www.capes.gov.br/images/ stories/download/avaliacao/com_conj_edu_ensi.pdf>. Acesso em: 12 maio 2015.

CUNHA, M. I. da. O tema da formação de professores: trajetórias e tendências do campo na pesquisa e na ação. Educação e Pesquisa, São Paulo, v. 39, n. 3, p. 609-625, 2013. 
O protagonismo controverso dos mestrados profissionais ...

DIAS, R. E. Ciclo de políticas curriculares na formação de professores no Brasil (1996-2006). 2008. 248 f. Tese (Doutorado em Educação) - Faculdade de Educação, Universidade do Estado do Rio de Janeiro, Rio de Janeiro, 2008.

DINIZ-PEREIRA, J. E. Formação docente nos Estados Unidos: aliança conservadora e seus conflitos na atual reforma educacional norte-americana. Educação \& Sociedade, Campinas, v. 29, n. 102, p. 233-252, 2008.

FREITAS, L. C. Crítica da organização do trabalho pedagógico e da didática. Campinas: Papirus, 1995.

FREITAS, H. C. L. de. A (nova) política de formação de professores: a prioridade postergada. Educação \& Sociedade, Campinas, v. 28, n. 100, p. 1203-1230, 2007. (Número especial).

GATTI, B. A. Análise das políticas públicas para formação no Brasil, na última década.

Revista Brasileira de Educação, Rio de Janeiro, v. 13, n. 37, p. 57-70, 2008.

GATTI, B. A. Formação de professores no Brasil: características e problemas. Educação \& Sociedade, Campinas, v. 31, n. 113, p. 1355-1379, 2010.

INSTITUTO NACIONAL DE ESTUDOS E PESQUISAS EDUCACIONAIS ANÍSIO TEIXEIRA. Sobre o Enem. [S.l: s.n.], 2011. Disponível em: <http://inep.gov.br/web/ enem/sobre-o-enem>. Acesso em: 10 out. 2013.

KUENZER, A. Z. O ensino médio no plano nacional de educação 2011-2020: superando a década perdida? Educação \& Sociedade, Campinas, v. 31, n. 112, p. 851-873, 2010.

- A formação de professores para o ensino médio: velhos problemas, novos desafios.

Educação \& Sociedade, Campinas, v. 32, n. 116, p. 667-688, 2011.

. As políticas de formação: a constituição da identidade do professor sobrante.

Educação \& Sociedade, Campinas, v. 20, n. 68, p. 163-183, 1999.

LAGE, M. A. G.; URZETTA, F. C.; CUNHA, A. M. de O. Formação continuada de professores: entre os limites e os silêncios dos programas de formação. In: ENCONTRO NACIONAL DE PESQUISA EM EDUCAÇÃO EM CIÊNCIAS, 8., 2011, Campinas. Anais... Campinas: ABRAPEC, 2011. 1 CD-ROM.

MAUÉS, O. C. A política da OCDE para a educação e a formação docente: a nova regulação? Educação, Porto Alegre, v. 34, n. 1, p. 75-85, 2011.

OSTERMANN, F.; REZENDE, F. Projetos de desenvolvimento e de pesquisa na área de ensino de ciências e matemática: uma reflexão sobre os mestrados profissionais. Caderno Brasileiro de Ensino de Física, Florianópolis, v. 26, n. 1, p. 66-80, 2009.

PEREIRA, T. V.; VELLOSO, L. Um salto para a performatividade: sentidos atribuídos à qualidade da educação. Ensaio: avaliação de políticas públicas educacionais, Rio de Janeiro, v. 20, n. 74, p. 73-88, 2012. Disponível em: <http://dx.doi.org/10.1590/S010440362012000100005>. Acesso em: 12 maio 2015. 
SANTOS, L. L. C. P. A implementação de políticas do banco mundial para a formação docente. Cadernos de Pesquisa, São Paulo, n. 111, p. 172-181, 2000.

SCHAFER, E. D. A. Impacto do mestrado profissional em ensino de física da UFRGS na prática docente: um estudo de caso. 2013. Tese (Doutorado em Ensino de Física) - Instituto de Física, Universidade Federal do Rio Grande do Sul, Porto Alegre, 2013. Disponível em: < http://hdl.handle.net/10183/78481>. Acesso em: 12 maio 2015.

SCHÄFER, E. D. A.; OSTERMANN, F. Autonomia profissional na formação de professores: uma análise de entrevistas realizadas num mestrado profissional em ensino de física. Revista Electrónica de Enseñanza de las Ciencias, Vigo, v. 12, n. 2, p. 287-312, 2013a. Disponível em: < http://reec.uvigo.es/volumenes/volumen12/reec_12_2_4_ex696. pdf $>$. Acesso em: 12 maio 2015.

. O impacto de um mestrado profissional em ensino de física na prática docente de seus alunos: uma análise bakhtiniana sobre os saberes profissionais. Ensaio: Pesquisa em Educação em Ciências, Belo Horizonte, v. 15, n. 2, p. 87-103, 2013b. Disponível em: <http://hdl.handle.net/10183/95130>. Acesso em: 12 maio 2015.

SCHEIBE, L. O conselho técnico-científico da educação básica da CAPES e a formação docente. Cadernos de Pesquisa, São Paulo, v. 41, n. 144, p. 812-825, 2011.

- Valorização e formação dos professores para a educação básica: questões desafiadoras para um novo plano nacional de educação. Educação \& Sociedade, Campinas, v. 31, n. 112, p. 981-1000, 2010.

SCHWARTZ, L. B.; REZENDE, F. A qualidade do ensino de ciências na voz de professores da educação profissional técnica de nível médio. Ensaio: Pesquisa em Educação em Ciências, Belo Horizonte, v. 15, p. 73-95, 2013.

TRAVITZKI, R. Resultados do Enem refletem desigualdades comuns no país. O Globo, Rio de Janeiro, 21 out. 2013. Disponível em: <http://oglobo.globo.com/sociedade/educacao/ resultados-do-enem-refletem-desigualdades-comuns-no-pais-10445682>. Acesso em: 11 maio 2015.

UNIVERSIDADE FEDERAL DO RIO GRANDE DO SUL. Mestrado profissional em ensino de física. [Porto Alegre, 2001]. Disponível em: <http://www.if.ufrgs.br/ppgenfis/ mestrado_profissional/informacoes.html?curso=0>. Acesso em: 14 maio 2015.

ZEICHNER, K. M. Uma análise crítica sobre a "reflexão" como conceito estruturante na formação docente. Educação \& Sociedade, Campinas, v. 29, n. 103, p. 535-554, 2008.

Artigo recebido em 24/06/14. Aceito em 18/12/14. 